Original Article

\title{
A comparison of the function, activity and participation and quality of life between down syndrome children and typically developing children
}

\author{
Hee-Kyoung Jung, PT, MSc1), EunJung Chung, PT, PhD²), Byoung-Hee Lee, PT, PhD ${ }^{3)^{*}}$ \\ 1) Graduate School of Physical Therapy, Sahmyook University, Republic of Korea \\ 2) Department of Physical Therapy, Andong Science College, Republic of Korea \\ 3) Department of Physical Therapy, Sahmyook University: 815 Hwarang-ro, Nowon-gu, Seoul 01795 , \\ Republic of Korea
}

\begin{abstract}
Purpose] To compare function, activity, participation, and quality of life of Down syndrome children and typically developing children according to age. [Subjects and Methods] A total of 16 Down syndrome children and 20 children with typical development were included as subjects for this study. International Classification of Functioning, Disability, and Health (ICF) Child and Youth version (CY) developed by the World Health Organization (WHO) and a questionnaire were used to measure children's functioning, activity, and participation. To measure quality of life, KIDSCREEN 52-HRQOL questionnaire was used in this study. [Results] ICF-CY function, activity, participation, and quality of life showed statistically significant differences between Down syndrome children and typically developing children. Down syndrome children with higher functions showed higher activities and participation. Higher function, activity and participation features were correlated with better quality of life. Higher function resulted in better quality of life. [Conclusion] Function, activity, participation, quality of life, and several common factors of Down syndrome children depend on the ability of children. Function of Down syndrome children affects their activity, participation, and quality of life. Activities and participations also affect quality of life. Therefore, children's functional aspect is the foundation for quality of life.

Key words: Down syndrome, ICF-CY, Quality of life
\end{abstract}

(This article was submitted Apr. 3, 2017, and was accepted May 24, 2017)

\section{INTRODUCTION}

Down syndrome (trisomy 21) is the most common genetically defined cause of intellectual disability. Almost 10,000 children are born with Down syndrome in the United States each year (one in 691 live births; prevalence of 10.3 per 10,000) ${ }^{1 \text { ) }}$. Down syndrome children might have cognitive deficits that can influence their performance of motor task ${ }^{2}$.

Handicapped Down syndrome children have difficulties in activity participation. They only have 50\% of physical strength compared to their peers, restricting them from being mixed with typical developing children. The degree of damage of cognitive deficit, age, and functional areas including self-management, locomotion, and sociality all can affect activity participation of a Down syndrome child ${ }^{3}$.

The World Health Organization (WHO) has developed an International Classification of Functioning, Disability and Health (ICF) to classify health and health-related components of well-being, including physical function and structure, activity and participation, environmental factors, and personal factors. These components interact with one another ${ }^{4)}$. ICF Child and Youth version (ICF-CY) is an extended version of the ICF. It includes child development as an additional health and health-related component.

*Corresponding author. Byoung-Hee Lee (E-mail: 3679@syu.ac.kr) 
Handicapped children want to improve their quality of life and perform their given social roles as normal children. However, physical movement level of a child not only restricts their social participation and activity, but also acts as an important factor affecting their quality of life ${ }^{5}$. In fact, their quality of life has been perceived as an important evaluation area in treatment ${ }^{6}$.

Therefore, the objective of this study was to compare ICF-CY function, activity, participation, and quality of life of Down syndrome children and typically developing children. Results obtained from this study could provide basic data necessary for developing intervention program to improve the quality of life of down syndrome children. In addition, this study evaluated and established goals. They provide helpful data for therapists, Down syndrome children, and their parents.

\section{SUBJECTS AND METHODS}

A total of 36 children were included for this study as subjects, including 16 Down syndrome children and 20 typically developing children. Participants were divided into two groups: before school-aged (4-7 years) and school-aged child (8-12 years). For Down syndrome children, inclusion criteria for were: (1) ability to walk 20 meters without assistance, (2) ability to comply with researchers' and guardians' instructions, and (3) permission was obtained from parents for participating in this study. Exclusion criteria were: (1) visual or auditory problem, and (2) a major history of disease or surgery.

For typically developing children, inclusion criteria were: (1) ability to comply with researchers' and guardian's instructions, and (2) permission was obtained from parents for participating in this study. Exclusion criteria were: (1) visual or audial problem, and (2) musculoskeletal disease, history of taking medicine related to musculoskeletal illness within 6 months, or with surgical experience. Of the 16 Down syndrome children included in this study, 7 were males and 9 were females. Their mean age was $6.8 \pm 1.8$ years. Their mean height was $90.6 \pm 26.5 \mathrm{~cm}$. Their mean weight was $15.4 \pm 6.3 \mathrm{~kg}$. Of the 20 typically developing children, 9 were males and 11 were females. Their mean age was $8.0 \pm 2.4$ years. Their mean height was $119.5 \pm 20.3 \mathrm{~cm}$. Their mean weight was $26.3 \pm 11.1 \mathrm{~kg}$. There was no significant difference in any of these characteristics between the two groups. The present study was approved by Sahmyook University Institutional Review Board. The objective of the study and its requirements were explained to subjects. All participants provided written parental consent in accordance with the ethical principles of the Declaration of Helsinki.

ICF-CY checklist is a summary of core sections of ICF-CY. It has been used to evaluate disability and health conditions in children and youth. The present study only reported data of body function, activity, and participation using formative factors of ICF-CY for ages of 7-12 years considering ages of our subjects and the purpose of this study. Eight areas of bodily function were evaluated and nine areas were included for the evaluation of activity and participation ${ }^{7}$. Each section was scored from 0 (indicating no difficulty in performance) to 4 (indicating a need for full assistance).

Health-related quality of life (HRQOL) is generally conceptualized as a multidimensional construct encompassing domains including psychological, mental, social, and spiritual areas of life ${ }^{8)}$. Korean version of KIDSCREEN 52-HRQOL is a tool for standardized life quality evaluation. It was developed by Ravens-Sieberer et al. ${ }^{9)}$ and modified by Hong ${ }^{10)}$ to fit Korean circumstances. It was answered by their parents. For quality of life evaluation, total scores of each item were calculated. Higher scores indicated higher HRQOL and wellbeing. The Korean version of KIDSCREEN 52-HRQOL has a Cronbach-alpha value ranging from 0.77 to 0.95 . It has been found to be suitable for use in Korean adolescents ${ }^{10)}$. In this study, the Korean version of KIDSCREEN 52-HRQOL was used after excluding school environment and financial resources because this study included preschoolers.

All statistical analyses were performed using SPSS, version 19.0 (SPSS Inc., Chicago, IL, USA). General characteristics were presented as frequencies and percentages. Average and standard deviations were also provided. Independent t-test was used to analyze changes in dependent variables between groups. Pearson's correlation coefficient was used to assess relationships of function, activity, participation, and quality of life of Down syndrome children. Statistical significance was set at $\mathrm{p}<0.05$.

\section{RESULTS}

Differences in function section of ICF-CY checklist were statistically significant $(\mathrm{p}<0.05)$ between Down syndrome children and typical developing children. Differences in activity and participation section of ICF-CY checklist were also statistically significant $(\mathrm{p}<0.05)$ between Down syndrome children and typical developing children. Differences in quality of life between the two groups were also statistically significant $(\mathrm{p}<0.05)$ (Table 1$)$. Regarding the correlation among function, activity, and participation in Down syndrome children, higher functions were correlated with higher activities and participation $(\mathrm{r}=0.952, \mathrm{p}<0.05)$. Function, activity, and participation features were significantly correlated with quality of life ( $\mathrm{r}=$ $-0.514, p<0.05)$. High functions were significantly correlated with high quality of life $(r=-0.505, p<0.05)($ Table 2$)$.

\section{DISCUSSION}

The objective of this study was to compare function, activity, participation, and quality of life between Down syndrome children and typically developing children. These children were divided into two groups (preschool age and school age). The 
Table 1. Comparison of function, activity and participation, and quality of life of ICF-CY ( $N=36)$

\begin{tabular}{llcc}
\hline & & DS $(\mathrm{n}=16)$ & TD $(\mathrm{n}=20)$ \\
\hline Function & Before school-aged child & $9.7(7.0)$ & $0.0(0.1) * *$ \\
& School-aged child & $6.1(4.5)$ & $0.0(0.0)^{*}$ \\
Activity and participation & Before school-aged child & $17.6(6.9)$ & $0.0(0.1)^{* * *}$ \\
& School-aged child & $13.4(6.9)$ & $0.0(0.0)^{* *}$ \\
\multirow{2}{*}{ Quality of life } & Before school-aged child & $58.9(4.7)$ & $91.7(9.4)^{* * *}$ \\
& School-aged child & $68.6(12.0) *$ & $94.5(6.9) * * *$ \\
\hline
\end{tabular}

Values are means (SD). DS: Down syndrome child; TD: typically developing children; Before school-aged child: 4-7 age child; School-aged child: $8-12$ age child; ${ }^{*} \mathrm{p}<0.05,{ }^{* *} \mathrm{p}<0.01,{ }^{* * *} \mathrm{p}<0.001$

Table 2. Correlation between function, activity and participation and quality of life in Down syndrome child $(\mathrm{N}=16)$

\begin{tabular}{lccc}
\hline Categories & Quality of life & Function & Activity and participation \\
\hline Quality of life & 1 & & \\
Function & -0.505 & 1 & \\
Activity and participation & $-0.514^{* *}$ & $-0.952^{* *}$ & 1 \\
\hline$* \mathrm{p}<0.05, * * \mathrm{p}<0.01$ & & &
\end{tabular}

typically developing children showed higher function levels than Down syndrome children. The lower mental function (1.31 points) in Down syndrome children might be due to storage and recall ability problem in Down syndrome children.

Craniofacial malformation present in Down syndrome children might affect language and auditory development. Down syndrome children show retardation in all developmental areas including cognition, language, and physical development. In language development, both receptive language and expressive language are retarded ${ }^{11)}$. The most important characteristic related to language problem of Down syndrome children is the difference between receptive and expressive language. They have poor ability to express the language than their ability to understand the language ${ }^{12}$.

They also have difficulties in receptive language due to their poor auditory processing ability. However, they generally have more difficulty in expressive language due to muscle problem. In general, $60-75 \%$ of Down syndrome children have such difficulties while $25-30 \%$ of Down syndrome children show language understanding and production corresponding to their cognitive level. However, $5 \%$ of Down syndrome children have defects in both understanding and production compared to their cognitive level. In general, communication skills of Down syndrome children are delayed for about 2 years compared to those of typically developing children. However, they show individual differences in starting language and performance thereafter ${ }^{11)}$. In this study, Down syndrome children showed an average score of 0.77 for neuro-musculoskeletal and movement-related function. Compared to typically developing children, Down syndrome children might have lower functional level due to hypotonic muscles, excessive ligament relaxation ${ }^{13)}$, and lack of sensory integration ability.

In comparison with typically developing children, Down syndrome children showed significant $(\mathrm{p}<0.05)$ differences in all areas of activity and participation of ICF-CY checklist. Down syndrome children showed low activity and participation due to the lack of executive function, including low cognitive levels of memory, initiation and suppression of response, problem solving, and planning ${ }^{14)}$.

The functional level of a child has been considered as an important factor that affects his or her quality of life ${ }^{5)}$. Previous studies about quality of life of handicapped children have mostly compared areas of quality of life regarding to physical activities rather than evaluating or comparing general happiness related to functional leve $\mathrm{l}^{15}$. In addition, most studies regarding quality of life have been focused on adult patients. There has been nearly no research that evaluates the quality of life regarding children and adolescent diseases.

In this study, KIDSCREEN 52-HRQOL questionnaire was used to measure children's quality of life. Since this study included preschoolers, the evaluation was performed by excluding school life and money problems ${ }^{9,}$ 10). Results of this study showed that there were significant differences in all areas of quality of life $(p<0.05)$ between Down syndrome children in comparison with typically developing children. Down syndrome children showed lower quality of life than typically developing children. Sabaz et al. ${ }^{16)}$ have reported that cognition of children with developmental disorder is closely related to their quality of life regarding their health. They found that children with developmental disorder and intellectual disability showed significantly lower scores in emotional happiness, social function, and behavior compared to typically developing children ${ }^{16)}$. The present study showed similar results. In this study, the quality of social and psychological life was higher than that of physical life in Down syndrome children. However, the quality of physical life was higher than that of social and psychological life in typically developing children, consistent with results of a previous study ${ }^{17)}$. Therefore, quality of life was different between Down syndrome children and typically developing children. 
Results of correlation analysis among functions, activities, and participation revealed that higher function of Down syndrome children was significantly correlated with higher activity and participation $(\mathrm{r}=0.952, \mathrm{p}<0.05)$. In addition, their function, activity, and participation features were correlated with their quality of life $(\mathrm{r}=-0.514, \mathrm{p}<0.05)$. Moreover, high function is correlated with high quality of life $(r=-0.505, \mathrm{p}<0.05)$.

Physical movement level of handicapped children has been found to be an important factor that affects their quality of life ${ }^{5)}$. Daily activity participation levels of handicapped children are diverse according to damage degree ${ }^{18)}$. Results of this study showed that functional and physical level of children can significantly affect their activity, participation, and quality of life, similar to results of previous studies. While it is true that physical level affects the quality of life of handicapped children, it can also be affected by the environment of parents or children. That is, although difference in physical movement level of children affects their participation in daily life, kindergarten, school, and social life, this can be improved by improving functional aspect of children. Based on our results, function, activity, participation, and quality of life of Down syndrome children should be improved by treatment to enhance their physical function through parent education and appropriate use of physical assist devices.

This study has several limitations. First, results of this study can only be generalized to Down syndrome children with similar characteristics. Second, the sample size was small, leading to reduced statistical power. In addition, this study did not evaluate their IQ scores, basic motor skills, or basic ADL abilities, although these factors might influence the function, activity and participation, and quality of life of children with Down syndrome. Therefore, further study with larger sample size of Down syndrome children is needed to investigate the correlation between IQ scores, basic motor skills, basic ADL abilities, function, activity and participation, and quality of life of Down syndrome children.

In conclusion, functional level of Down syndrome children is an important factor that affects their activity, participation, and quality of life. Function, activity, participation, and quality of life of Down syndrome children differed according to their physical level. Their activity and participation function became higher when their function was higher. Their activity and participation became better as their quality of life was higher. Their quality of life became better when their functional level was higher.

\section{REFERENCES}

1) Shin M, Besser LM, Kucik JE, et al. Congenital Anomaly Multistate Prevalence and Survival Collaborative: Prevalence of Down syndrome among children and adolescents in 10 regions of the United States. Pediatrics, 2009, 124: 1565-1571. [Medline] [CrossRef]

2) Amadó A, Serrat E, Vallès-Majoral E: The role of executive functions in social cognition among children with Down syndrome: relationship patterns. Front Psychol, 2016, 7: 1363. [Medline] [CrossRef]

3) Ostensjø S, Carlberg EB, Vøllestad NK: Everyday functioning in young children with cerebral palsy: functional skills, caregiver assistance, and modifications of the environment. Dev Med Child Neurol, 2003, 45: 603-612. [Medline] [CrossRef]

4) WHO: World Health Organization. International Classification of Functioning, Disability and Health. Geneva: World Health Organization, 2001.

5) Davis E, Waters E, Mackinnon A, et al.: Paediatric quality of life instruments: a review of the impact of the conceptual framework on outcomes. Dev Med Child Neurol, 2006, 48: 311-318. [Medline] [CrossRef]

6) Marchal JP, Maurice-Stam H, Hatzmann J, et al.: Health related quality of life in parents of six to eight year old children with Down syndrome. Res Dev Disabil, 2013, 34: 4239-4247. [Medline] [CrossRef]

7) WHO: International classification of functioning, disability and health: children \& youth version: ICF-CY, 2007.

8) Graves RJ, Graff JC, Esbensen AJ, et al.: Measuring health-related quality of life of adults with down syndrome. Am J Intellect Dev Disabil, 2016, 121: 312-326. [Medline] [CrossRef]

9) Ravens-Sieberer U, Gosch A, Rajmil L, et al.: KIDSCREEN-52 quality-of-life measure for children and adolescents. Expert Rev Pharmacoecon Outcomes Res, 2005, 5: 353-364. [Medline] [CrossRef]

10) Hong SD, Yang JW, Jang WS, et al.: The KIDSCREEN-52 quality of life measure for children and adolescents (KIDSCREEN-52-HRQOL): reliability and validity of the Korean version. J Korean Med Sci, 2007, 22: 446-452. [Medline] [CrossRef]

11) Berglund E, Eriksson M, Johansson I: Parental reports of spoken language skills in children with Down syndrome. J Speech Lang Hear Res, 2001, 44: 179-191. [Medline] [CrossRef]

12) Witecy B, Penke M: Language comprehension in children, adolescents, and adults with Down syndrome. Res Dev Disabil, 2017, 62: 184-196. [Medline] [CrossRef]

13) Galli M, Cimolin V, Pau M, et al.: Relationship between flat foot condition and gait pattern alterations in children with Down syndrome. J Intellect Disabil Res, 2014, 58: 269-276. [Medline] [CrossRef]

14) Horvat M, Croce R, Tomporowski P, et al.: The influence of dual-task conditions on movement in young adults with and without Down syndrome. Res Dev Disabil, 2013, 34: 3517-3525. [Medline] [CrossRef]

15) Shelly A, Davis E, Waters E, et al.: The relationship between quality of life and functioning for children with cerebral palsy. Dev Med Child Neurol, 2008, 50: 199-203. [Medline] [CrossRef]

16) Sabaz M, Cairns DR, Lawson JA, et al.: The health-related quality of life of children with refractory epilepsy: a comparison of those with and without intellectual disability. Epilepsia, 2001, 42: 621-628. [Medline] [CrossRef]

17) Wake M, Salmon L, Reddihough D: Health status of Australian children with mild to severe cerebral palsy: cross-sectional survey using the Child Health Questionnaire. Dev Med Child Neurol, 2003, 45: 194-199. [Medline] [CrossRef]

18) Cans C: Prevalence and characteristics of children with cerebral palsy in Europe. Dev Med Child Neurol, 2002, 44: 633-640. [Medline] 